\title{
EXPERIÊNCIA ESTÉTICA E O DISPOSITIVO DO CINEMA NA FORMAÇÃO
}

\author{
AESTHETICAL EXPERIENCE AND CINEMA AS DISPOSITIF IN EDUCATION
}

\author{
Monica Fantin ${ }^{1}$
}

\begin{abstract}
Resumo
O texto parte de uma reflexão sobre a experiência estética e sua relação com o cinema destacando alguns elementos do percurso estético que envolve a intuição, imaginação, conhecimento e corporeidade. Em seguida, discute algumas teorias do cinema e os possíveis entendimentos como arte, indústria, linguagem e dispositivo para situar diversas compreensões de tal conceito e a ideia de um cinema como dispositivo na formação. A potência de tal dispositivo pode ser evidenciada a partir de experiências e narrativas desencadeadas em pesquisa com crianças e na formação docente de estudantes universitários. Por fim, o texto tece algumas considerações sinalizando a possibilidade outros percursos estéticos e formativos com e sobre cinema na escola e no território.
\end{abstract}

Palavras-chave: cinema; experiência estética; dispositivo; formação.

\begin{abstract}
The text takes into account the reflection of aesthetical experience and its relation to cinema emphasising some of the elements of the aesthetical paths which entails intuition, imagination, knowledge and corporeity. Secondly it addresses some cinemat theories and the possible contribution of arts, industry, language and dispositif to diversify the notion of such a concept and the idea of cinema as a dispositif in education. The power of such a dispositif can be witnessed from experience and narrative discovered in researches with children and in teacher training courses for universities students. Finally the text highlights the possibility of other aesthetical and educational paths regarding cinema in schools and territory.
\end{abstract}

Keywords: cinema; aesthetic experience; dispositive; education.

\section{Introdução}

Diante de tantas possibilidades de pensar a relação entre cinema, estética e educação, o texto toma como base algumas reflexões tecidas inicialmente no contexto de uma pesquisa

\footnotetext{
${ }^{1}$ Universidade Federal de Santa Catarina (UFSC) - email: monica.fantin@ufsc.br
}

Revista Devir Educação, Lavras, vol.2, n.2, p.33-55 jul./dez., 2018. 


\section{OO DEVIR EDUCAÇÃO}

ISSN: 2526-849X

sobre cinema, crianças e educação que se desdobraram em outras possibilidades de formação. $\mathrm{O}$ artigo apresenta alguns olhares sobre a experiência estética e o audiovisual a partir da intuição, imaginação, conhecimento que a fruição de filmes possibilita, juntamente com alguns aspectos da corporeidade envolvida neste processo. Ao percorrer certas teorias do cinema, diante da multiplicidade semântica que tal conceito envolve, aqui o cinema é entendido como arte, indústria, dispositivo e linguagem, o que nos leva ao diálogo com diversos entendimentos e olhares. A partir de alguns recortes, o texto apresenta algumas narrativas que evidenciam aspectos da experiência do cinema em uma pesquisa desenvolvida com crianças e na formação universitária. Por fim, destaca alguns indícios e singularidades da experiência estética do cinema na educação.

\section{Experiência estética e cinema: possíveis olhares}

A relação entre estética e cinema ${ }^{2}$ pode ser entendida na tradição de uma reflexão teórica sobre as artes em geral, visto que muitas teorias do cinema se referem à estética. Estética, do grego aisthesis, significa percepção, sensação ${ }^{3}$. Como disciplina autônoma, a estética surgiu no século XVIII, envolvendo o estudo da beleza artística e de temas relacionados ao sublime, grotesco, cômico, prazeroso, e junto com a lógica e a ética, a estética compõe a tríade de ciências normativas da Filosofia, que estabelece as regras a respeito do verdadeiro, do bom e do belo, lembra Stam (2003).

$\mathrm{Na}$ modernidade, a estética é vista como "reinvindicação da corporeidade e da sua peculiar força cognoscitiva e produtiva: percepção, imaginação, fantasia, sentimento, intuição, gosto, gênio, todos os modos de conhecer-produzir o mundo, conectado ao corpo, impensável sem o corpo" (DIODATO, 2012, p.19). E na contemporaneidade, a estética pode ser interpretada a partir da experiência de localização e ampliação, da experiência do encontro com a obra de arte e da reflexão sobre a experiência estética, como experiência corpo-mundo e espaço-tempo da relação que a experiência estética envolve, destaca o autor.

\footnotetext{
${ }^{2}$ Nesse texto nossa compreensão sobre o cinema também se estende ao âmbito mais amplo do audiovisual, resguardadas suas especificidades históricas, contextuais e conceituais.

${ }^{3}$ Para Baumgarten, um dos precursores do conceito, a estética se construiu como ciência relacionada ao âmbito do "sensitivo", que é mais amplo que o âmbito do "sensível" e indica tanto sensação como percepção. Ver Diodato (2012, p.16)
} 


\section{OO DEVIR EDUCAÇÃO}

ISSN: 2526-849X

Desse modo, a experiência estética vai além do consumo de arte, que também tem seu valor, e pode manifestar-se como atividade criativa e como inspiração o que requer meios expressivos que na maioria das vezes envolvem palavras ou conceitos (SORLIN, 1997). Mas a representação de ideias estéticas ultrapassa o conceito, daí a dificuldade em definir a estética (PAREYSON,2002), e a importância de contextualizá-la histórica e socialmente (EAGLETON,1993).

Na relação de apreensão e expressão do belo através do cinema/audiovisual, SORLIM (1997) esclarece a importância de discutir a relação que se estabelece entre a enunciação de um sistema de significados e a intuição artística. Ele discute o devir do belo no campo audiovisual, integrando o cinema no conjunto de produtos destinados à tela.

Privilegiando a perspectiva da participação ativa dos fruidores/espectadores, Sorlin pergunta quando e como quem vê e escuta põe em jogo a sua "intuição estética". E sem propor regras nem modelo de análise, para o autor, essa intuição seria uma atitude de abertura na construção de um percurso estético que por sua vez seria formado por intuição (momento inicial da percepção, que provoca prazer, gozo e emoção), juízo/gosto (percepção construída e determinada pelo contexto sociocultural que está relacionada a uma ideia de beleza) e opinião (momento interpretativo, a avaliação a posteriori) voltados à construção da experiência estética. (FANTIN, 2013, p.543).

A intuição seria aquilo que nos toca, um despertar da atenção que interroga a obra, incerto sobre o caminho a percorrer e pronto para iniciar um percurso sem gratificação imediata, mas como possibilidade de descoberta. Este primeiro momento pode ser abordado com a pergunta: "O que naquele filme, programa, me chama atenção, independente do que transmite ou do modo com que transmite?”. O gozo iria além, sugerindo uma superação, uma sensação de excesso, um esforço e a compensação que tal esforço comporta. O prazer viria espontaneamente da graça e da clareza da obra, da facilidade do seu significado diretamente acessível, mas também, por vezes da conquista que a dificuldade de compreensão também propicia. A emoção, traço característico da experiência estética, seria um sentido forte, uma sensação intensa e uma necessidade de reação que se manifesta em situações diversas, frente ao belo, ao feio, à alegria, à desventura, à incerteza, ao perigo e à infelicidade. Emoção que seria motor do desejo que nos impulsiona a uma atitude indagadora. Assim, a ideia de 


\title{
OO DEVIR EDUCAÇÃO
}

ISSN: 2526-849X

intuição define a aproximação estética no seu momento inicial, em que a obra não se impõe por si ao espectador mas provoca a emoção na disponibilidade de captá-la.

Nessa perspectiva, "a estética nada tem a ver com uma particular qualidade inerente a certas produções audiovisuais: ela se define através de convenções de uma sociedade mas só quem procura consegue construí-la" (SORLIN, 1997, p.15). Assim, a experiência estética é uma relação que se estabelece entre sujeito e obra, não é algo imanente. É uma relação dialética que envolve a contradição entre sujeito, elementos da obra em si e para si que propicia a experiência da significação. Algumas nuances de tal relação com o belo são elucidadas em Baudelaire:

\begin{abstract}
O belo é constituído por um elemento eterno e invariável, cuja quantidade é excessivamente difícil determinar, e de um elemento relativo, circunstancial, que será, se quisermos, sucessiva ou combinadamente, a época, a moda, a moral, a posição. Sem esse segundo elemento, que é como o invólucro aprazível, palpitante, aperitivo do divino manjar, o primeiro seria indigerível, inapreciável, não adaptado e não apropriado à natureza humana. Desafio qualquer pessoa a descobrir qualquer exemplo de beleza que não contenha esses dois elementos (BAUDELAIRE, 1996, p.10).
\end{abstract}

Diante da dificuldade que as mais diversas correntes e escolas filosóficas se depararam ao definir o belo, talvez seja mais fácil relacionar com a questão do feio como par indissolúvel. "O belo é uma completude, um raio de eternidade que transcende a história e se põe além da vida, e é o seu oposto, o feio, que reflete a transformação, a fuga do tempo, a incessante decomposição da matéria" (SORLIN, 1997, p.21). No desenvolvimento da estética do feio, os atos de chamar a atenção para algo diferente, de mostrar ou esconder, de denunciar, revelar e ignorar ainda que pelo confronto, pela tensão, pelo conflito, pelo (anti)conformismo tiveram papel importante na construção dos cânones da beleza. Tal estética também envolve ironia, paródia, deformação, pois configura incômodo e perturbação (Fantin, 2011).

Entre sentimentos múltiplos e incertos do belo, valores, estilos e significados construídos na relação que estabelecemos com aquilo que nos toca, seu oposto, o feio, também provoca outras reações de inquietação, remetendo a ritmos, harmonias e composições outras. Desse modo, a categoria do belo é uma peça, uma tessela de um mosaico na 


\section{OO DEVIR EDUCAÇÃO}

ISSN: 2526-849X

construção do conhecimento. Beleza que também pode ser pensada como emoção, como sentimento que se torna componente fundamental do pensamento. A beleza não habita as coisa mas reside no encontro, nas relações, na sensibilidade, na mente que contempla, no conhecimento, enfim, na nossa relação com o mundo e também na íntima e silenciosa exploração do eu.

$\mathrm{Na}$ tessitura da experiência estética que envolve a intuição, "a ciência intuitiva é conhecimento estético enquanto condição de possibilidade da potência da imaginação, visto que a imaginação não é um gênero de conhecimento que deve ou pode ser superado." (DIODATO, 2012, p.161). Ao relacionarmos as possibilidades de imaginação e conhecimento que o filme promove, estamos nos referindo a uma concepção de conhecimento estético que envolve "um saber próprio daqueles momentos em que pensar e sentir são inseparáveis, em que o corpo e a mente estão entrelaçados, interconectados.(...)"(DIODATO, 2012, p.157). Ou seja, envolve "um saber de uma experiência que por sua natureza e atividade, é um conhecer e junto um fazer, um construir, um manipular, um gostar, e que é exemplificável na atividade artística, mas também em certas atividades sociais e relacionais, e em sentido lato, da esfera política”. ( idem, 2012, p. 157).

Essas possibilidades de sentir, perceber, conhecer, imaginar sintetizam também a experiência estética que o cinema propicia e que educa. Como diz Xavier (2008, p.13), "cinema que educa é um cinema que (nos) faz pensar", sobre o cinema em si e sobre as mais variadas experiências que ele coloca em jogo. E aqui acrescentamos um cinema que emociona, diverte, transforma e faz sentir, pensar, vibrar e que em contextos educativos também pode assumir o sentido de uma "montagem didática" (FANTIN, 2018).

No cinema, a sensibilidade do fruidor/espectador pode ser traduzida em cada gesto, cada manifestação e não se refere apenas a uma circunstância que exprime códigos e elementos da produção audiovisual, pois amplia os modos de ver e perceber tais elementos. E o instigante deste percurso é que cada espectador, por mais desatento ou seguro que seja em sua aproximação, deixa-se envolver naquilo que nem sempre o filme explicita. $\mathrm{O}$ filme com sua história, seus significados e sua linguagem procura antes de tudo uma apaixonante e coenvolvente ilusão de imediaticidade através de suas cores, formas, movimentos, sons. Nessa experiência estética, o espectador pode ser tomado por uma força misteriosa, experimentando uma sensação de distanciamento em relação àquilo que é proposto. A aparência do mundo à 


\section{OO DEVIR EDUCAÇÃO}

ISSN: 2526-849X

qual o espectador está habituado, os sinais e as representações do seu cotidiano parecem diferentes, fora do lugar, e essa sensação não coincide com qualquer hábito de padronização. É uma quebra de regras, como alegorias e mônadas que, ao captar o instante, se abrem para o inusitado e o insignificante retirando os elementos da significância (FANTIN, 2011).

No espectador, a experiência estética como intuição inicial também pode permanecer de alguma forma e se transformar. E isso ocorre quando aparece o desejo de refazer ou repetir o caminho "apenas" pelo prazer provocado ou de recompor o percurso para captá-lo melhor. Quando há interesse em uma elaboração maior, o juízo intervém e ativa impressões e intencionalidades que podem ir além, analisar e conhecer. Essa forma de apropriação pode se manifestar como interpretação, opinião e possível (re)criação, fruto da ambigüidade e da dinâmica do percurso estético que envolve também a identificação-negação do espectador que utiliza e nega, e a interpretação-recriação que o espectador avalia e da qual se apropria. Cores, timbres, luzes, gestos e histórias oscilam entre aquilo a que o filme se refere e a impressão que ele suscita, e muitas vezes adquire vida própria, desenvolvendo-se, modificando-se, completando-se e contradizendo-se na imaginação de cada um.

A obra de arte é um desafio e uma provocação para a inteligência, e suscita prazer e emoção, despertando no espectador a convicção de que é possível, ou melhor, de que é necessário não se limitar às primeiras impressões, e pôrse, ao contrário, mais profundamente em relação com ela (SORLIN, 1997, p.59).

Nessa perspectiva, o caráter da obra de arte parece ser feito para tornar-se uma experiência estética, em que a potência da arte provoca um impulso único na pessoa que a experimenta num momento de sua vida, reportando-se ao mesmo tempo à totalidade de sua existência. Uma vivência pode ser tornar experiência intuitiva, reflexiva e contemplativa, e em diferentes espaços da formação também pode ser entendida como experiência de aprendizagem que remete ao sentido de experiência como iniciação.

Ao analisar experiência e iniciação na obra filosófica de Merleau-Ponty, Chauí (1994) diferencia o sentido das palavras experiência, que significaria "sair de si", e iniciação "entrar para si, origem", e enfatiza impossibilidade de opor interioridade e exterioridade no pensamento do autor, para quem a consciência seria "originariamente encarnada". 
A experiência já não pode ser o que era para o empirismo, isto é, passividade receptiva e resposta a estímulos sensoriais externos, mosaicos de sensações que se associam mecanicamente para formar percepções, imagens, ideias; nem pode ser o que era para o intelectualismo, isto é, atividade de inspeção intelectual do mundo. Percebida, doravante, como nosso modo de ser e de existir no mundo, a experiência será o que ela sempre foi: iniciação aos mistérios do mundo (CHAUI, 1994, p.473).

Algumas dimensões dessa experiência e iniciação nos leva a pensar no cinema como dispositivo na formação.

\section{Cinema como dispositivo na formação}

O que é o cinema, afinal? É arte, entretenimento, cultura? É narrativa, linguagem, dispositivo? É instrumento, meio ou fim? É tudo isso e muito mais? Para responder a tais questões dificilmente encontraríamos as respostas definitivas na história do cinema diante de tantas teorias explicativas e seus modos de pensar o cinema, sua estrutura, suas linguagens e seus significados na relação com o espectador. Explicar como se constrói a relação filmeespectador requer caracterizar, discutir e avaliar o tipo de experiência que o cinema propicia, diz Xavier (2003). Implica pensar como suas imagens tornam-se atraentes e legíveis e de que forma conseguem a mobilização de afetos, afirmando-se, segundo ele, mais como instância de valores e reconhecimentos ideológicos, do que como manifestação de consciência crítica.

Num breve passeio por algumas teorias do cinema ${ }^{4}$, junto com Stam (2003) começamos com a descrição do cinema clássico com a explicação de H. Munsterberg, V. Pudovkin e B. Balázs que procurava se afirmar como arte; passamos pelo cinema como um novo dado de percepção fruto da construção de um novo olhar e de uma nova linguagem através do "cinema feiticeiro, anticartesiano e de avant-garde" de J. Epstein, do "cine-olho"

\footnotetext{
${ }^{4}$ Para Stam (2003), a teoria nesse campo estuda o cinema como meio, como linguagem cinematográfica e como dispositivo, discutindo ainda a natureza do texto cinematográfico e sua recepção. Por sua vez, Casetti (2004) distingue as teorias ontológicas, metodológicas e temáticas do cinema.
} 


\section{OO DEVIR EDUCAÇÃO}

ISSN: 2526-849X

de D. Vertov e da relação cinema-psicologia em Merleau-Ponty; circulamos pelo "cinema intelectual" da montagem de atrações de S. Eisenstein; pelo cinema visionário da câmera extensão do corpo de S. Brackage; pelo "cinema como instrumento de poesia" e "autorismo" com F. Truffaut e do maravilhoso nos surrealistas como L. Buñuel. Interrogamos o cinema a partir de sua representação com A. Bazin. Discutimos os processos subjacentes ao charme do "cinema sonho, magia, imaginário" e a participação afetiva do espectador com E. Morin. Analisamos o cinema e a psicanálise com C. Metz e seu "significante imaginário", as fronteiras da experiência cinematográfica com H. Mauerhofer e refletimos sobre os "efeitos ideológicos do aparelho de base", e o dispositivo do cinema com J.L. Baudry. Também questionamos "a grande teoria" nos trabalhos de Deleuze, Imagem-Movimento e ImagemTempo, em que estabelece outros conceitos para entender o cinema e suas relações com o tempo, espaço, memória. Aliás, para Stam, Deleuze percebe o cinema como "instrumento filosófico, um gerador de conceitos e um produtor de textos que traduz o pensamento em termos audiovisuais (...)” (STAM, 2003, p.284). Nas relações entre cinema, corpo, cérebro, pensamento, "pensar é aprender o que pode um corpo não-pensante, sua capacidade, suas

atitudes ou posturas. É pelo corpo (e não mais por intermédio do corpo) que o cinema se une com o espírito, com o pensamento", enfatiza Deleuze (2005, p.227).

Enfim, em diálogo com estes e tantos outros cineastas e estudiosos do cinema com certeza poderíamos chegar a diferentes práticas artísticas cinematográficas marcadas por rupturas com os códigos da indústria cultural para encontrar outras inspirações e propostas de outros cinemas. No percurso do "pré" ao "pós" cinema que A. Machado (1997) sugere, hoje as tecnologias digitais promovem outras possibilidades de entendimento, relação e fruição convergindo e atravessando territórios e campos de expressão artísticas que remetem a um "cinema expandido" que cruza as fronteiras da arte-mídia e avança em territórios e espaços do contemporâneo até então não imaginados.

A esse respeito, é crescente a presença de situações cinematográficas em espaços distintos da sala de cinema (museus, galerias, mostras de arte contemporânea) em que o espaço da exposição torna-se espaço de projeção/exibição de obras audiovisuais. Assim, os dispositivos da projeção, os códigos sonoros e visuais da imagem em movimento e os significados da narrativa atuam no espaço expositivo que "se integra ao espaço fílmico e viceversa, e dessa imbricação de funções decorre uma expansão sobre o que se entende e se define por cinema"(MOREIRA, 2015, p.1).

Revista Devir Educação, Lavras, vol.2, n.2, p.33-55 jul./dez., 2018. 


\section{OO DEVIR EDUCAÇÃO}

ISSN: 2526-849X

Nesse quadro, o entendimento plural que situa o cinema e suas nuances como arte, indústria, dispositivo e linguagem (FANTIN,2013) afirma uma prática social e uma experiência ética-estética que envolve "narração, representação, ideologia e também desejo e posição simbólica" (METZ, 2003, p.403). Sendo o filme um discurso, é próprio dele "apagar as marcas da enunciação", o que potencializa a noção do "dispositivo cinematográfico."

O termo dispositivo no cinema foi utilizado por Baudry para designar a situação espectatorial no cinema e engloba "todos os aspectos da experiência na sala de projeção" (XAVIER, 2003, p.411). Na teoria do espectador cinematográfico, para Baudry, pensar o cinema como dispositivo significava apontar as características que regulam a relação do espectador com a obra, relações mentais, espaciais e temporais. Assim, como um mecanismo que dispõe de certas funções, muitas instituições sociais podem ser estudadas como dispositivos.

Entender o cinema como dispositivo significa vê-lo como um dispositivo de representação com seus mecanismos de organização do espaço, dos papéis assumidos e da própria mecânica de produção da imagem: câmera, tela em que se projeta, sala escura, reações dos espectadores, modos de produção dos efeitos de sentidos previstos na estratégia do diretor-narrador e outros. Como noção que tem se tornado cada vez mais freqüente na reflexão teórica para se referir à disposição dos elementos constituintes de uma obra, o dispositivo estaria ligado à técnica em que as imagens são dispostas ou à técnica que cria imagens (DUBOIS, 2004).

Para Metz, o dispositivo cinematográfico como instituição social envolve posição simbólica, imaginário e um jogo de identificações que regulam o funcionamento da mente e do inconsciente. Ele também relaciona alguns níveis de identificação no cinema - a identificação primária - com o próprio dispositivo como um fetiche (METZ, 2003, p.418) e destaca que o dispositivo também envolve as relações entre ideologia, desejo e economia que são muito poderosas no cinema como discurso.

Observe-se que aqui não se trata do mesmo conceito de dispositivo explicitado na obra de Foucault. Se a teoria do dispositivo origina-se da discussão entre cinema, psicanálise e teorias do estruturalismo, aos poucos foi migrando para outros contextos com novas formulações: na teoria da "caixa preta" de V. Flusser; na descrição do filme-dispositivo de J.L Comolli dentro do conceito de cinema-veritè; no dispositivo da videoarte formulado por A. 


\title{
OO DEVIR EDUCAÇÃO
}

ISSN: 2526-849X

M.Duguet; e de forma mais ampla no pensamento de M. Foucault e G. Deleuze, lembra Bentes (2005).

O dispositivo é um termo técnico decisivo na estratégia de pensamento de Foucault, lembra Agamben (2015), sobretudo quando ele começa a se ocupar do tema da governabilidade ou de governo de si. Na hipótese do autor, embora Foucault não tenha elaborado propriamente uma definição, aproxima-se de tal conceito em uma entrevista:

\begin{abstract}
Através deste termo [dispositivo] tento demarcar, em primeiro lugar, um conjunto absolutamente heterogêneo que engloba discursos, instituições, estruturas arquitetônicas, decisões regulamentares, leis, medidas administrativas, enunciados e científicos, proposições filosóficas, morais, filantrópicas. Em suma, o dito e o não dito são elementos do dispositivo. $\mathrm{O}$ dispositivo é a rede que se pode estabelecer entre esses elementos (FOUCAULT, 1988, p.244)
\end{abstract}

Para AGAMBEN (2015, p.37), “os dispositivos devem sempre implicar um processo de subjetivação, isto é, devem produzir o seu sujeito" (2015, p.37). E diante das múltiplas possibilidades semânticas sobre o conceito dispositivo, o autor nos convida a deixar a filologia foucaultiana em suspenso para situar os dispositivos em outro cenário. Ao generalizar a ampla classe de dispositivos foucaultianos, o autor chama de dispositivo "qualquer coisa que tenha de algum modo a capacidade de capturar , orientar, determinar, interceptar, modelar, controlar e assegurar os gestos, as condutas, as opiniões e os discursos dos seres viventes" (idem, p.39).

Desse modo, além de prisões, escolas, fábricas, disciplinas, medidas jurídicas que evidenciam relação com poder estão a caneta, a escrita, a literatura, a filosofia, a navegação, os computadores, os celulares e a própria linguagem que é um dos mais antigos dispositivos que teve a consciência de se deixar capturar. E é nessa lista que incluímos o cinema. Afinal, como dia Agamben (2015, p.43): "Na raiz de todo o dispositivo está, deste modo, um desejo demasiadamente humano de felicidade, e a captura e a subjetivação deste desejo, numa esfera separada, constituem a potência especifica do dispositivo".

Nos últimos anos, discute-se a noção de dispositivo como estruturas narrativas capazes de produzir acontecimentos nas imagens e no mundo, pensando sobretudo na relação das 


\section{OO DEVIR EDUCAÇÃO}

ISSN: 2526-849X

novas tecnologias dos audiovisuais e suas formas de criação, organização e possibilidade de sentido das imagens contemporâneas. Segundo BENTES (2005, p.9), "pensar as obras e filmes-dispositivos é pensar as condições de possibilidades de narrativas". Ao refletir sobre a relação mídia-arte, a autora se refere à retomada da teoria dos dispositivos dos anos 70, que é revista em novos termos e "usada na análise de inúmeras obras que vêm problematizar a projeção e a percepção clássicas, criando outra relação com o espectador interator e distintas experiências de espaço e tempo.”(idem, p.10). Por sua vez, Migliorin (2005) discute o dispositivo como "estratégia narrativa capaz de produzir acontecimento na imagem e no mundo". Para ele, pensar como as novas tecnologias do audiovisual são organizadas em dispositivos de criação “ é pensar também o estatuto da imagem contemporânea, a possibilidade e o sentido da produção de novas imagens"(idem, p.1). E nessa perspectiva, podemos ir além e entender a produção de imagens e ações.

Entre os entendimentos do cinema como dispositivo que mobiliza ações, Bentes (2005) retoma a teoria de Bergson sobre a relação entre percepção e ação que posteriormente foi retomada por Deleuze (2005) argumentando que de certa forma ele antecipa e reafirma o que as tecnologias interativas explicitam sobre a percepção como momento do agir. Ou seja, o ver seria uma solicitação à ação e o perceber seria o agir sobre algo. Assim, o olhar interpela nosso esquema sensório-motor de ação-reação a partir dos estímulos que recebemos, e é o que experimentamos no papel de “espectador-ator" imerso num espaço multissensorial que o cinema propicia. Aliás, Benjamin (1996) enfatizava aspectos de tal relação quando se referia a algo novo o que surgia com o "impacto" dos meios óticos e acústicos promovidos pelos aparelhos técnicos do cinema e as novas formas de experiência sensível que propiciava.

A partir de estudos que analisam processos mentais de pessoas em interação com as telas, Kerkhove (2009, p.26) destaca que as telas do cinema, da televisão e outras telas "se comunicam sobretudo com nosso corpo, não com a mente", fazendo referências às imagens que se comunicam com a mente inconsciente. Inspirado em tal reflexão, Ferrés (2014, p.19) complementa que "as telas geram uma intensa atividade mental e uma boa parte desta atividade tem lugar na mente submergida, no labirinto das emoções. E nisto reside sua força sedutora e sua potência socializadora".

Num contexto em que as teorias das mídias, da história da arte e do cinema constroem os nexos entre estilos artísticos, história da tecnologia e história da experiência sensível e 


\section{OO DEVIR EDUCAÇÃO}

ISSN: 2526-849X

corpórea, "a percepção e a cognição incorporadas fornecem outro modelo explicativo da recepção cinematográfica" (FERRARI; FANTIN, 2017, p.19). ${ }^{5}$

Ao estudar o poder da imagem, sua força de atração sua capacidade de replicar e simular formas de experiência que incidem no movimento, o neurocientista V. Gallese e o teórico do cinema M. Guerra encontram no cinema o cruzamento dos pontos de vista estético, cultural, social e político. Quando perguntam pelo tipo de relação intersubjetiva entre os espectadores e os mundos possíveis da ficção que o cinema representa no imaginário coletivo, Gallese e Guerra (2015) percorrem a origem da intersubjetividade - tema amplamente tratado pela teoria, pela crítica e pela filosofia do cinema de modo a revitalizar e inovar tais questões à luz das neurociências cognitivas e da neuroestética. Nesta perspectiva, os circuitos cerebrais estariam extremamente ligados à corporeidade, e nossa corporeidade não seria reduzível a um objeto físico mas se realizaria na esfera da experiência, como um corpo que age, sente, conhece e constrói experiência a partir de nossas relações com o mundo. A corporeidade aqui, desenvolve um papel decisivo nas práticas de simulação, ação e sensação presente na vida cotidiana, nas experiências estéticas e particularmente no cinema.

Assim, diante da clássica pergunta "o que é o cinema", os autore respondem com outras perguntas que nos ajudam a entender outros âmbitos da relação cinema, dispositivo e educação:

O que significa 'ver' um filme? Até que ponto e em que medida a irrealidade percebida da ficção cinematográfica se afasta da modalidade com que nos reportamos à realidade cotidiana em que estamos imersos? Por que a ficção narrativa do cinema frequentemente nos atinge e emociona mais que a vida real? Em que medida a nossa identidade, história pessoal e a contingente condição cultural de espectadores condicionam a fruição do filme? O quanto é importante considerar o nível de co-envolvimento empático e corpóreo para compreender como funciona a tecnologia do cinema? Qual é o melhor método para estudar o co-envolvimento com as imagens e sons do filme e a consequente imersão na ficção narrativa cinematográfica? (GALLESE; GUERRA, 2015, p.14)

\footnotetext{
${ }^{5}$ Ver fundamentos e relações do fenômeno de incorporação e cinema em Ferrari;Fantin (2017, p.25-6)
} 


\section{OO DEVIR EDUCAÇÃO}

ISSN: 2526-849X

Perguntas que certamente contribuem para enriquecer e renovar nossa compreensão sobre o cinema, sobre o dispositivo e suas relações. Afinal, na relação com o cinema, discutir as possibilidades do pensamento em torno dos dispositivos, das percepções e das ações, dá visibilidade aos elementos estruturantes das obras e suas relações com o espaço, aos modos como mobiliza o corpo do espectador/observador, aos modelos mentais que trama, tornandose ao mesmo tempo objeto, discurso e mediação.

E essa potência do dispositivo cinema pode ser observada em algumas experiências de pesquisa e formação.

\section{Experiências e narrativas sobre cinema na pesquisa e na formação}

Diversas experiências e pesquisas com crianças e jovens na escola e fora dela demonstram a potência do cinema como dispositivo da formação e mediação educativa e cultural revelando uma crescente preocupação com a relação cinema-educação. Como seria difícil fazer uma síntese razoável no espaço deste artigo, como recorte, trazemos algumas narrativas que revelam tanto a experiência estética do cinema na especificidade de uma pesquisa com crianças, como na singularidade de experiências na formação universitária.

\subsection{A experiência das crianças e suas relações com o cinema}

A partir de uma pesquisa qualitativa desenvolvida com crianças em contextos brasileiros (CB) e contextos italianos (CI), que envolveu exibição do filme, aplicação de um questionário e entrevistas coletivas com crianças, e um percurso didático sobre cinema e produção de audiovisual com crianças na escola do contexto brasileiro (FANTIN, 2011), é possível refletir sobre diversos aspectos da experiência das crianças em relação ao filme $O$ Mágico de $\mathrm{Oz}$. Os fragmentos escolhidos relacionam-se à experiência estética e ao cinema como dispositivo promovendo narrativas que se construíram a partir do que as crianças disseram sobre o que é cinema, sobre o que mais gostaram no filme, o que não gostaram e outras percepções sobre os efeitos especiais e sobre a música do filme. Neste recorte, 


\section{OO DEVIR EDUCAÇÃO}

ISSN: 2526-849X

trazemos também alguns diálogos e sínteses que a experiência do cinema promove, e que não se esgota no momento da fruição.

[Sobre o que é o cinema]

"É quando vê a tela e tudo escuro dá um arrepio na gente e um lugar cheio de crianças. Isso é cinema para mim” (Prisciane, 9, CB)

“Cinema não é somente um passatempo, mas também um ponto de vista diferente, idéias diversas, concentração, atração, é introduzir-se em um mundo novo e fantástico" (Valentina, $9, \mathrm{CI})$

[O que mais gostou no filme]

"Quando a Dorothy foi pelo caminho das pedras amarelas eu senti coragem de ir sozinha ao mercado... Por que antes eu não ia” (Olívia, 8, CB)

"O modo com que Dorothy era frágil e indefesa mas ao mesmo tempo determinada e decidida. Me admirou o Mágico de Oz que fez compreender, a quem tinha necessidade, que todos têm coragem, coração e cérebro" (Valentina, 10, CI)

Enquanto as crianças brasileiras revelam as cenas que mais gostaram: "na hora do ciclone", "quando os desejos foram alcançados", "quando Dorothy volta para casa", "quando ela derrota a bruxa", "quando ela encontra os amigos", as crianças italianas destacam "quando fica colorido”, "quando Dorothy encontra os amigos”, "quando eles vão ao castelo da bruxa", "quando se livram da bruxa", "quando ela volta para casa”. Embora citem a preferência por personagens, na descrição das cenas o "ficar colorido" é o que aparece em primeiro lugar. Aliado a isso, o ciclone é um divisor de águas no filme, pois além da ruptura na história, abre a seqüência que leva o filme a ficar colorido. Tal cena foi indicada como "efeitos especiais" e a importância dessa seqüência para o filme foi percebida pelas crianças pelo impacto e tensão da cena do ciclone, pelo deslumbre quando o filme fica colorido, e pelo seu significado na história e suas rupturas. Podemos evidenciar tais aspectos a partir do diálogo entre as criança italianas:

Gabriele: $O$ que mais me impressionou foi a cenografia, o Mágico de $O z$ e o tornado[ciclone]. A cenografia é belíssima. 


\section{OO DEVIR EDUCAÇÃO}

ISSN: 2526-849X

Valentina: Para mim, ao invés, impressionou o comportamento de Dorothy, que parecia frágil, porém depois, quando enfrentava inclusive seus medos, era determinada e forte. E também a cenografia e as músicas eram estupendas.

Pietro: Eu gostei mais do furacão e do Mágico de Oz.

Sara: A cenografia, a música e toda a paisagem.

Sofia: Eu gostei verdadeiramente de tudo, porém a parte em branco e preto e as canções em que os personagens se apresentavam, um pouco.

[Do que não gostou no filme ]

Se o que as crianças mais gostaram pode ser entendido como um momento de intuição inicial da experiência estética, o par complementar seria o desprazer demonstrado pelas crianças. Enquanto para algumas crianças o "não gostar" relacionou-se às cenas de conteúdo do filme, para outras o desprazer associou-se à forma, tanto em relação às canções quanto às cores. Outras crianças mencionaram a insatisfação com o final do filme, o fato de tudo ter sido só um sonho de Dorothy, e tal frustração se relaciona à adaptação do livro, observada no diálogo das crianças italianas:

Giulia: (...) quando se lê se imagina tudo diferente daquilo que o diretor do filme imaginou quando leu o livro. Em vez disso, ao assistir o filme, te espanta, fica um pouco assim, porque imaginou tudo diferente. E eu tinha imaginado uma coisa diferente.

Brigitte e Sofia: No livro diz que ela retorna para casa mas que não era um sonho.

Elisa: Mas qual livro que vocês leram? Aquele que tem na escola? Eu li um livro que o final era quase igual ao filme. O filme tinha a mesma estrutura igual, mas alguns detalhes mudavam e eu imaginava uma coisa bem diferente...

Brigitte: O filme é mais rico em particularidades que o livro não tem.

Sofia: Aquele que eu li dizia que no final ela voltava para a casa mas que não era um sonho.

[Do preto-e-branco ao colorido e os efeitos especiais]

A passagem do preto-e-branco ao colorido é uma ruptura no filme, tanto pelo aspecto visual como pela semântica, já que a mudança das cores também significa a entrada a outro mundo, o mundo além do arco-íris. As hipóteses revelam os sentimentos vividos durante o filme e outras experiências de vida em que os argumentos das diferentes percepções referem- 


\section{OO DEVIR EDUCAÇÃO}

ISSN: 2526-849X

se a um sentido maior explicitado nos dois contextos, que é a passagem do mundo real ao mundo da fantasia.

A associação entre cores e sentimentos explicita alegria: "Oz é alegria, por isso é colorido", e a ausência de cores é o oposto, como dizem duas crianças italianas: "Para mim o preto-e-branco exprime tristeza, e o colorido exprime felicidade" (Simone, 10), "Kansas era triste, infeliz e privada de cores e alegria de viver e Oz era colorido, alegre e feliz" (Valentina, 10). Mas tal associação também sinaliza outros entendimentos em ambos contextos: "Porque a casa no Kansas ficava em lugar pobre e a casa de Oz era num lugar muito rico” (Ana Carolina, 8, CB), "Porque Oz era um mundo mágico” (Joana, 8, CB), “Em preto-e-branco é tristeza e melancolia; ao invés, o colorido é alegria e felicidade porque Dorothy foi embora" (Sofia, 10, CI).

Sobre os efeitos especiais, que cumprem importante papel na história da cinematografia, no referido filme eles foram precursores de muitos outros que hoje surpreendem pela potencialidade de recursos. E a maioria das crianças disse ter gostado e achado os efeitos especiais bons, bonitos e interessantes, "deram vida ao filme, senão não dava pra fazer este filme” (Ion, 8, CB). Uma fala chama a atenção, pela espontaneidade com que apareceu, quando a menina diz: "é interessante porque não sabia o que era efeitos especiais e agora sei" (Caroline, 9, CB), revelando que ao assistir o filme no contexto da pesquisa, aprendeu o que são os efeitos especiais, confirmando a importância da mediação, seja na compreensão do filme seja na experiência estética e cinematográfica das crianças. Aliás, algumas crianças italianas também contextualizam e relativizam os efeitos especiais no filme: "para o ano que foram feitos são bonitos" (Tomaso, 9) ou "por ser um filme dos anos 40 os efeitos especiais eram extraordinários" (Martina, 9). Tais respostas sugerem o sentido de uma possível atualização estética dos efeitos especiais, com ou sem os recursos da tecnologia atual atuando no imaginário infantil, como por exemplo, no diálogo das crianças brasileiras sobre o estatuto de realidade dos filmes:

Alisson: Pra mim é ilusão, truque de computador.

Xandler: É real.

Alexsandra: Pra mim é ilusão também.

Aline: É, mas Matrix não é.

Alisson: Orra [sic]... já dá até pra ver que é computador. Matrix é ilusão. 


\section{OO DEVIR EDUCAÇÃO}

ISSN: 2526-849X

Xandler: Não é ilusão. Eles seguram o carinha de verdade.

Alisson: O cara cai do prédio, bate o nariz no chão e não morre...

Bruna: De vez em quando é real, os filmes são contados pelas pessoas e daí eles fazem o filme, mas de vez em quando é ilusão por causa que eles tentam mostrar pras pessoas poderem aprender um pouco.

Tainá: É, de vez em quando é ilusão e também outros são verdade. O Titanic é verdade...

Augusto: Não sei. Quando começam a atirar nas pessoas, começa sair sangue, eu acho que é mentira.

Tainá: É óbvio né, é catchup...

Thais: É claro, eles não vão matar uma pessoa só pra fazer um filme...

Augusto: É lógico... Mas se (eu) ganhar um dinheiro bom, pode até dar uns tiros...

Thais: Mas como que tu vai ficar com o dinheiro daí? (Risos...)

Tais questões demonstram também o aspecto da corporeidade presente na experiência com o cinema parecer transportar o espectador para dentro do filme e criar "uma certa impressão de realidade" (METZ, 2003, p.107), evidenciada na síntese do menino: “O filme é real, só que nem sempre as coisas que acontecem nele é real” (Raí, 8).

\section{[Música]}

Diversos aspectos chamaram a atenção das crianças em relação à música do filme e apesar da importância em seu contexto de produção, na fruição parece assumir outros significados. Sendo um musical, quando os personagens cantavam, algumas crianças consideraram "legal, bonitas, divertidas, engraçadas e alegres", e outras "chatas". Todos mencionaram o fato de as canções serem em inglês como algo que dificultou sua compreensão. Ou ainda, "as músicas eram bonitas, mas as canções um pouco chatas” (Anita C, 9, CI), “As músicas fazem sonhar" (Laura, 9, CI) .

Enfim, as impressões manifestadas no prazer e no desprazer, no impacto provocado pela passagem para as cores, pelos efeitos especiais e pela música, mostram que assistir ao filme e conversar sobre ele, mais que uma vivência, pode consistir em uma experiência no sentido benjaminiano, que vimos anteriormente. Para além do sentir, as crianças pensaram, narraram, escreveram e compartilharam emoções e percepções. Como algumas meninas italianas demonstraram, “... foi lindo saber o que dizem os outros” (Elsa,10), "Sim, é verdade, 


\section{OO DEVIR EDUCAÇÃO}

ISSN: 2526-849X

o filme e a entrevista foram bons também para saber o que eles [os amigos] dizem, porque às vezes se lhes perguntamos certas coisas eles não respondem, assim, quando respondem aos outros podemos saber" (Martina, 9).

E isso revela que a experiência estética não se esgota no momento da fruição, como podemos perceber quando as crianças falam sobre a participação na pesquisa:

“Eu gostei de participar da pesquisa porque eu aprendi sobre cinema. Agora eu sei o que é um plano americano" (Vinicius, 10),

"Digo primeiro que gostei de ter participado. Depois que eu achei uma coisa muito inteligente, porque pedir as coisas para as crianças e querer saber o que elas pensam é uma experiência bem diferente de perguntar para adultos. Você poderia ter perguntado para os adultos sobre o que eles pensam que as crianças acham. Mas ao contrario, você preferiu perguntar para nós sobre o que nós pensamos” (Chiara, 9)

"O que eu mais gostei foi ter ido ao cinema" (Gabriel, 10)

Enfim, nestes breves fragmentos e narrativas revela-se também o dispositivo do cinema atuando na construção das subjetividades e mobilizando o pensar.

\subsection{Experiências de estudantes com cinema na formação universitária.}

A partir de diversas propostas desenvolvidas em duas disciplinas de um curso de Pedagogia $^{6}$ - que entre outras atividades envolveram ciclos de exibições de filmes (ficção, documentário e outros), rodas de conversa e análise de filme, oficinas de produção de audiovisual e outras atividades -, trazemos alguns fragmentos das narrativas de estudantes da graduação para elucidar aspectos de tal experiência em que o cinema atuou como dispositivo da formação.

[Sobre os filmes que mais gostaram]:

\footnotetext{
${ }^{6}$ Disciplina eletiva Cinema, Infância e Educação a e disciplina obrigatória Educação e Infância do referido curso.
} 


\section{QO DEVIR EDUCAÇÃO}

ISSN: 2526-849X

"O filme de Tornatore é espetacular e riquíssimo, pois retrata as lembranças da infância e adolescência vivida por Salvatore. Um filme que aguça a vontade de conhece mais sobre cinema, que mostra um forte laço de amizade entre um idoso e uma criança, que fala sobre

filmes, cinema sobre cinema. É um filme sobre sonhos, sentimentos humanos, um filme universal, poético e atemporal" (sobre o filme Cinema Paradiso, de Giuseppe Tornatore, Itália, 1988)

"O que mais marcou no filme foi o garoto ter superado seus limites e se adequar ao novo modo de vida. A cena que chamou atenção é quando o garoto "recolhe" os sons da natureza para montar a história de filme, cada detalhe era perfeito naquela construção" (sobre o filme Vermelho como o céu, de Cristiano Bortone, Itália, 2006)

"Esse filme mexeu com minhas emoções, me fez ver o mundo de outra forma. A cena mais marcante foi a que o personagem começa a inventar os sons com um gravador da escola que ele pega escondido. Acredito que a música e os sons chamam atenção pois demonstram a sensibilidade das crianças cegas" (sobre o filme Vermelho como o céu, Cristiano Bortone, 2006).

"O filme marcou-me principalmente porque consegui identificar a maioria das minhas brincadeiras de infância, fui recordando os tempos de criança do longo de todo o filme. Espantou-me bastante a forma como as crianças brincavam e manobravam os materiais das brincadeiras. Achei curioso o fato do filme ser majoritariamente de imagens e sons, com a ausência muito marcante de falas ou explicações. As cenas que mais marcaram foram onde as crianças construíam os seus próprios brinquedos(...)Outro fator importante que me cativou bastante foi o fato da maioria das brincadeiras ser realizada em ambientes exteriores, com a presença de muita luz e claridade, sendo estes aspectos relevantes, reforçando a ideia da brincadeira livre e dando um brilho diferente às brincadeiras" (sobre o filme Territórios do brincar, de Renata Meirelles e David Reeks, Brasil, 2015)

"O filme "Pandorga" foi o que selecionei na vasta gama de filmes que assistimos, porque sendo intercambista, conhecer mais um pedaço desta mágica ilha onde vivo e estudo, fezme querer cada vez mais ficar cá . Pois a cultura do povo, tal como retratado no filme, apaixona qualquer ser humano. Não foi apenas o conteúdo que me cativou neste filme. As cores e as imagens fizeram com que meu olhar ficasse bem preso à tela. Tendo em conta a qualidade, a sequencia e o que elas demonstravam no real (...) A força do conteúdo cultural 


\section{OO DEVIR EDUCAÇÃO}

ISSN: 2526-849X

que o filme me estava a oferecer foi tanta, que dias a seguir fui a esse mesmo local, só para com os meus próprios olhos ver as imagens do filme" (sobre o filme A Pandorga e o peixe, de Katia Klock e Ivan Sá, Brasil, 2014)

"Aos poucos fui percebendo o intuito da exibição de filmes tão diferentes. Em um dos filmes a imaginação e a criatividade das crianças tomam conta, enquanto em outros, os contexto sociais nos quais as personagens estão envolvidas impossibilitam isso (como foi o caso de Song Song a a Pequena Gatinha). Em um dos filme a criança era apaixonada por cinema enquanto em outro era apaixonada por concurso de beleza... Esse filmes me fizeram parar para analisar cada contexto social e cada criança em suas especificidades: isso é educação (...) De fato, com o cinema o educador pode ir além do mundo" (em referência aos curtas Tanza, de Mehdi Charef, Bilú e João, de Katia Lund e Song Song e Pequena Gatinha de John Woo in Crianças Invisíveis (Itália, 2005), Vermelho Como o Céu, Cristiane Bortone, Itália, 2006, e A Pequena Miss Sunshine, de Jonathan Dayton, EUA, 2006)

[Sobre a avaliação das propostas que envolveram cinema, exibição de filmes e oficinas de produção em diferentes espaços]

"A nossa experiência com o curso foi espantosa, foi um resgate. Adorei a ligação cinemadisciplina, arte para o diálogo com infância que me interessa muito. No início estava apreensiva, não esperava muito, mas acabei sendo conquistada. O cinema, os filmes, as oficinas, tudo foi muito legal, mexeu muito comigo, tive vários insights e também o resgate de minha própria infância."

"O conteúdo do curso foi ótimo, sobre a infância e suas singularidades, mas destaco a forma de dar aula em relação aos filmes e vídeos. Você conseguiu isso, mostrar outras formas de dar aula e fazer a formação, não só aulas expositivas".

"Ter ido ao cinema com a turma foi demais. Eu nunca tinha ao cinema, nem assistido um filme 3D. Parecia que as imagens saíam da tela, que era tudo vivo. E a música também, transportava para dentro da história."

Como em certos filmes quando acabamos que assistir, oscilamos entre a vontade de falar e de silenciar... Neste momento, parece que tais fragmentos falam por si só. 


\section{Algumas considerações}

Neste artigo buscamos refletir sobre aspectos da experiência estética e sua relação com o cinema como dispositivo que desencadeia e promove outras formas de percepção e ação. Também trouxemos alguns fragmentos de narrativas sobre o cinema a partir de uma pesquisa com crianças e a partir de algumas propostas desenvolvidas no contexto de duas disciplinas de um curso de Pedagogia.

Diante das potências reveladas pelo dispositivo cinema na pesquisa e na formação docente, é possível vislumbrar outras experiências desencadeadas em cursos de formação permanente, em oficinas de produção de audiovisual, em projetos de extensão envolvendo cineclubes na universidade e no território. Possibilidades de fruição, análise e produção cinematográfica evidenciando autorias compartilhadas que envolvem um reconhecimento de si, do outro e do entorno. Múltiplas linguagens e sensorialidades construindo conhecimento e propiciando outras formas de participação na escola e pertencimento na cultura.

Nessa tessitura, consideramos que a experiência estética e formativa com o cinema propicia outros tipos de aprendizagem e de mediações na construção de um olhar, de um perceber e de um agir que transcende. Experiência que une beleza, estranhamento, arte, cultura, corporeidade e que promove as mais diversas formas de relação. Experiência de encontro, formação e significação que foi construída no contexto de uma interpretação singular.

\section{Referências}

AGAMBEN, Giorgio. O que é dispositivo. Chapecó: Argos, 2015.

AUMONT, Jacques et al. A Estética do filme. Campinas: Papirus, 1995.

BAUDELAIRE, Charles. Sobre a modernidade. Rio de Janeiro: Paz e Terra, 1996. 


\section{OO DEVIR EDUCAÇÃO}

ISSN: 2526-849X

BENJAMIN, Walter. Obras Escolhidas I: Magia e técnica, arte e política: ensaios sobre a literatura e história da cultura. 7. ed. São Paulo, Brasiliense, 1996.

BENTES, Ivana. Mídia-Arte: Estéticas da Comunicação e Modelos Teóricos. In Anais do XXVIII Congresso Brasileiro de Ciencias da Comunicação. INTERCOM. UERJ, Rio de Janeiro, 2005.

CASETTI, Francesco. Teorie del Cinema 1945-1990. 7. ed. Studi Bompiani, Milano, 2004.

CHAUI, M. Merleau-Ponty: obra de arte e filosofia. In NOVAES, A. Artepensamento. São Paulo: Companhia das Letras, 1994.

DELEUZE, Gilles. Cinema II: a imagem-tempo. São Paulo, Brasiliense, 2005.

DIODATO, Roberto. L'invisibile sensibile: itinerari di ontologia estética. Milano: Mimesis, 2012.

DUBOIS, Philippe. Cinema, vida, Godard. Cosac Naify: São Paulo, 2004.

EAGLETON, Terry. A Ideologia da Estética. Rio de Janeiro: Zahar, 1993.

FANTIN, Monica. Cinema e Imaginário Infantil: a mediação entre o visível e o invisível. Educação \& Realidade, v. 34, n. 2, p. 205-23, maio/ago. 2009.

FANTIN, Monica. Crianças, cinema e educação: além do arco-íris. São Paulo: Annablume, 2011.

FANTIN, Monica. Cinema, participação estética e imaginação. Revista Pedagógica, n. 30 vol. 01 - jan./jun. 2013.

FANTIN, Monica. Conhecimento estético, tecnologias da sensibilidade e experiências formativas de crianças, jovens e professores. In Revista Tempos e Espaços em Educação. V. 11, n. 26, p. 39-54, jul./set. 2018.

FERRARI, Rodrigo; FANTIN, Monica. Cinema e Incorporações: reflexões e possibilidades educativas. In Revista Digital do LAV. UFSM. Vol. 10, n. 2, p. 17-38, mai./ago. 2017.

FERRARI, Rodrigo. Ensinar-aprender cinema: percepção e cognição incorporada. Tese de Doutorado. UFSC/PPGE, Florianópolis, 2015.

FERRÉS, Joan. As pantallas y el cérebro emocional. Barcelona: Gedisa, 2014.

FOUCAULT, Michel. Microfisica do poder. 7. ed. Rio de Janeiro: Graal, 1988.

GALLESE, Vittorio; GUERRA, Michele. Lo schermo empático: cinema e neuroscienze. Milano: Raffaello Cortina, 2015.

KERKHOVE, Derrick. A pele da cultura: investigando a nova realidade eletrônica. São Paulo: Annablume, 2009. 
MACHADO, Arlindo. Pré-cinemas \& Pós-Cinemas. Campinas: Papirus, 1997.

METZ, Christian. O dispositivo cinematográfico como instituição social. In XAVIER, I. (org.) A experiência do cinema: antologia. Rio de Janeiro: Edições Graal: Embrafilme, 2003.

MIGLIORIN, Cesar. O dispositivo como estratégia narrativa. Anais da XIV COMPÓS. Niterói-RJ, 2005.

MOREIRA, Roberto. Experiências pioneiras em cinema expandido. In Revista Z Cultural. Disponível em: $\quad\langle$ http://revistazcultural.pacc.ufrj.br/experiencias-pioneiras-em-cinemaexpandido-de-roberto-moreira-2/ > (Acesso em 28/07/2018)

PAREYSON, Luigi. Estética. Teoria della formatività. 3. ed. Tascabili Bompiani, Milano: 2002.

SORLIN, Pierre. Estetiche dell'audiovisivo. La Nuova Itália, Firenze, 1997.

STAM, Robert. Introdução à teoria do cinema. Campinas: Papirus, 2003.

XAVIER, Ismail (org). A experiência do cinema: antologia. Rio de Janeiro: Graal: Embrafilme, 2003.

XAVIER, Ismail. Um cinema que educa é um cinema que (nos) faz pensar (entrevista). Educação \& Realidade, v. 33, n.1, 2008. 